\title{
Intestinal macrophages: differentiation and involvement in intestinal immunopathologies
}

\author{
Benjamin Weber • Leslie Saurer • Christoph Mueller
}

Received: 14 April 2009/Accepted: 11 May 2009/Published online: 17 June 2009

(C) Springer-Verlag 2009

\begin{abstract}
Intestinal macrophages, preferentially located in the subepithelial lamina propria, represent the largest pool of tissue macrophages in humans. As an adaptation to the local antigen- and bacteria-rich environment, intestinal macrophages exhibit several distinct phenotypic and functional characteristics. Notably, microbe-associated molecular pattern receptors, including the lipopolysaccharide (LPS) receptors CD14 and TLR4, and also the Fc receptors for IgA and IgG are absent on most intestinal macrophages under homeostatic conditions. Moreover, while macrophages in the intestinal mucosa are refractory to the induction of proinflammatory cytokine secretion, they still display potent phagocytic activity. These adaptations allow intestinal macrophages to comply with their main task, i.e., the efficient removal of microbes while maintaining local tissue homeostasis. In this paper, we review recent findings on the functional differentiation of monocyte subsets into distinct macrophage populations and on the phenotypic and functional adaptations that have evolved in intestinal macrophages in response to their antigen-rich environment. Furthermore, the involvement of intestinal macrophages in the pathogenesis of celiac disease and inflammatory bowel diseases is discussed.
\end{abstract}

Keywords Monocytes · Macrophages · Intestinal mucosa . Commensal flora

B. Weber $\cdot$ L. Saurer $\cdot$ C. Mueller $(\bowtie)$

Division of Experimental Pathology, Institute of Pathology,

University of Bern,

Murtenstrasse 31,

CH-3010 Bern, Switzerland

e-mail: christoph.mueller@pathology.unibe.ch

\section{Differentiation of monocyte/macrophage subsets}

Macrophages represent a functionally and phenotypically highly diverse cell population which is not only crucially involved in innate and adaptive immune reactions, but also in embryonic development, wound repair, and maintenance of local tissue homeostasis [1-3]. Macrophages, monocytes, and their lineage-committed bone marrow (BM) precursors constitute the mononuclear phagocyte system (MPS), which represents a complex cellular system across different organs.

Monocyte progenitors are continuously formed in the $\mathrm{BM}$. The myeloid differentiation process is associated with a progressive loss of differentiation potential. Multipotent hematopoietic precursors, such as lineage-committed precursors (Lin) $)^{-} \mathrm{Sca}_{-1}^{+}$, and c-kit $(\mathrm{CD} 117)^{+}[4,5]$, are precursors for the common myeloid progenitor cells [6] and the common lymphoid progenitor cells [7]. In CX3CR1EGFP transgenic mice [8], a subset of myeloid BM cells $\left(\mathrm{CD}_{115^{+}}, \mathrm{CX} \mathrm{CR}^{+}, \mathrm{CD} 117^{+}\right.$, and $\left.\mathrm{Lin}^{-}\right)$was identified as precursors for macrophages and dendritic cells (DC) but not for neutrophils [9]. These common progenitor cells of the MPS are, therefore, called myeloid lineage macrophage-DC progenitors (MDP). Upon adoptive transfer into the BM of recipient mice, MDPs differentiate into circulating monocytes $[9,10]$. After leaving the BM, monocytes circulate in the vasculature for several days before they enter their target tissue to complete their differentiation into macrophages (Fig. 1). The selective recruitment of blood monocyte subsets to peripheral sites of the body is crucial for maintaining the distinct populations of differentiated tissue macrophages [11]. Nevertheless, at least under steady-state conditions, local cell proliferation may also contribute to the replenishment at least of some tissue macrophage subsets [12]. As an example, Kupffer cells 


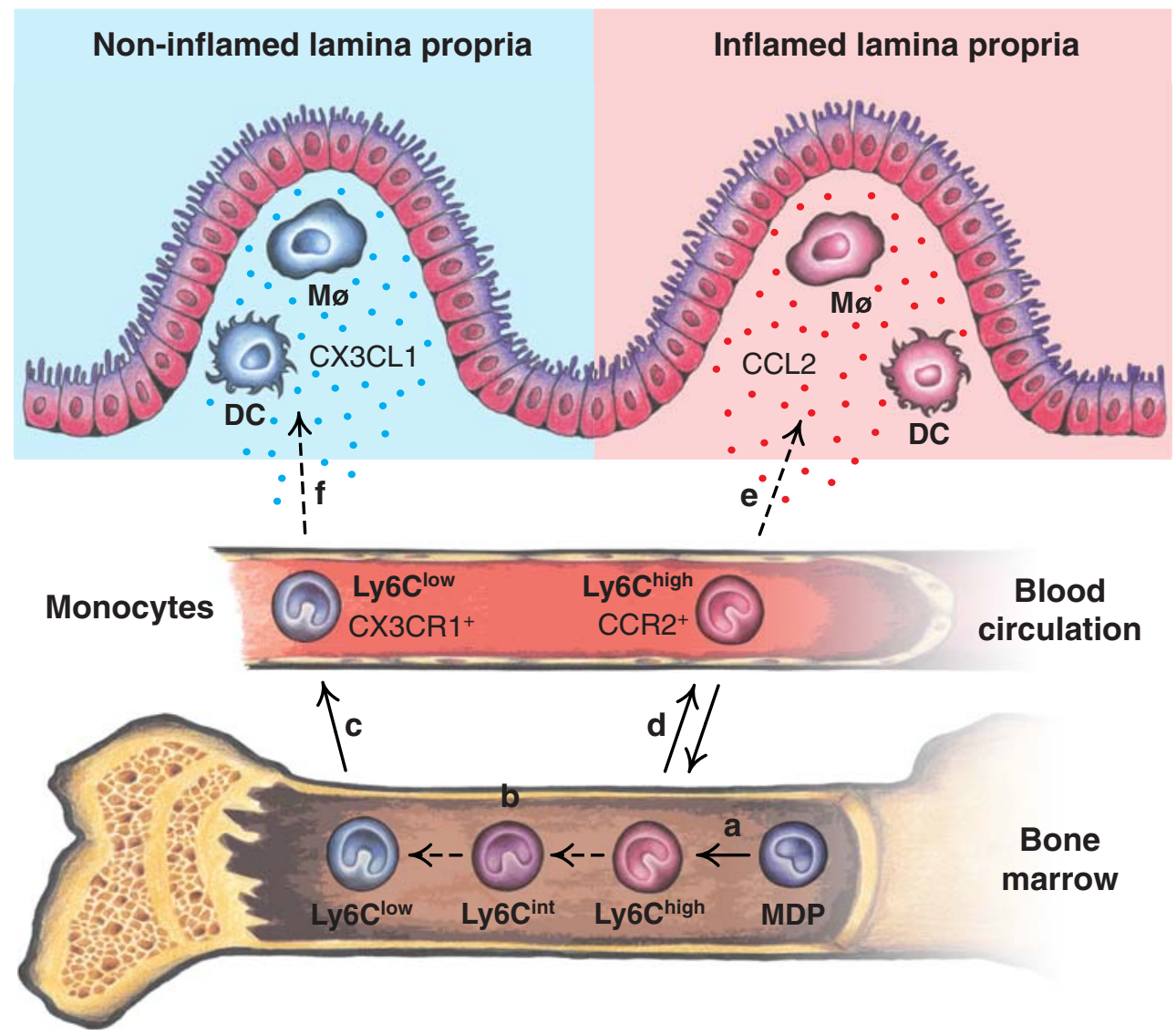

Fig. 1 Origin of monocytes and their differentiation into macrophages $(M \varnothing)$ and dendritic cells $(D C)$ in the intestinal lamina propria in mice. a MDP give rise to Ly6 $\mathrm{C}^{\text {high }} \mathrm{BM}$ monocytes [9]. b The conversion from Ly6 $\mathrm{C}^{\text {high }}$ to Ly6 $\mathrm{C}^{\text {low }}$ monocytes possibly takes place over an intermediate cell type $\left(\operatorname{Ly} 6 C^{\text {int }}\right)$ in the BM $[10,38]$. c BM monocytes are released into the peripheral blood circulation, while under homeostatic conditions (d), the majority of Ly $6 \mathrm{C}^{\text {high }}$ blood monocytes home back to the BM [10]. e Ly6 $\mathrm{C}^{\text {high }}$ monocytes express CCchemokine receptor $2(C C R 2)$ and may be recruited to sites of inflammation by responding to CC-chemokine ligand 2 (CCL2) [10,

[13], microglial cells [14], Langerhans cells [15], and alveolar macrophages $[16,17]$ were shown to also proliferate locally. In contrast to those tissue macrophages, intestinal macrophages were reported to be nonproliferating [18]. Remarkably, in contrast to effector cells of the adaptive immune system, the proliferative capacity of BM-derived macrophages is blocked after activation with interferon- $\gamma$ (IFN $\gamma)$ by a cyclin-dependent kinase $(\mathrm{Cdk})$ inhibitor [19].

Research on human cells has been restricted to in vitro studies and, thus, most data on the functional differentiation of monocyte/macrophage subsets were obtained in animal models. Monocyte heterogeneity is conserved between different species, and the functional commonality of these systems led to the identification of corresponding monocyte subsets in human, mouse, rat, and pig [12]. Adoptive cell transfer experiments and the availability of chemokine
20]. f Ly6 $\mathrm{C}^{\text {low }}$ monocytes express CX3C-chemokine receptor 1 $(C X 3 C R 1)$ and possibly replenish the tissue-resident $\mathrm{Mø}$ and DC populations by responding to cleaved $\mathrm{CX} 3 \mathrm{C}$-chemokine ligand 1 (CX3CL1). Note that CX3CL1 (fractalkine) is expressed by intestinal epithelial and endothelial cells [101-104], while CCL2 is mainly produced at sites of mucosal inflammation [105]. Solid arrows represent pathways that are supported by published data, while dashed arrows indicate proposed, still hypothetical pathways. Blue dots proteolytically cleaved CX3CL1, red dots CCL2. BM bone marrow, $M D P$ Mø-DC progenitor

receptor-deficient mouse lines were instrumental to obtain insight into the biological heterogeneity of monocytes and macrophages. Although the precise lineage relationships are not yet firmly established in detail, it is generally accepted that distinct subsets of BM and blood monocytes are the precursors of DCs, resident macrophages (i.e., macrophages that are located in the tissue under homeostatic conditions), and inflammatory macrophages (also named exudate macrophages), which are recruited to the tissues during inflammatory conditions. In mice, the "inflammatory" macrophages seem to be derived from a recruited, shortlived inflammatory subset of blood monocytes. These "inflammatory" monocytes are characterized by the high expression of CCR 2 and $\mathrm{Ly} 6 \mathrm{C}$ and intermediate expression of CX3CR1, while noninflammatory monocytes (CCR2 ${ }^{-}$, Ly6 $\mathrm{C}^{-}$, and $\mathrm{CX} 3 \mathrm{CR} 1^{\text {hi }}$ ) may differentiate into long-lived resident myeloid cells, including resident tissue macro- 
phages [20]. Jung et al. have generated a reporter mouse line in which the gene coding for the fractalkine receptor (CX3CR1) was replaced by a green fluorescent protein reporter gene [8]. Hence, in these CX3CR1-GFP mice, cells of the MPS compartment can be visualized and functionally distinct monocyte subsets can be distinguished (and fractionated) based on the differential expression of CX3CR1-GFP.

It is becoming increasingly evident that macrophages are functionally highly promiscuous and that the exerted functions are crucially determined by the local tissue microenvironment. Hence, the broad functional diversity of mononuclear phagocytes and the wide range of activating signals that may affect their functions is a characteristic attribute of this cell population $[12,21,22]$. This is reflected not only by the plasticity of the functional phenotypes of monocyte/macrophage subsets in vitro, but also by the diversity of functions exerted by macrophage subsets isolated ex vivo from tissues under physiological and inflammatory conditions. These functional and phenotypic adaptations are most prominent in resident macrophages of the intestinal mucosa and have evolved during the coevolution of the local immune system with the microbial flora of the gut lumen.

\section{Heterogeneity of the mononuclear phagocyte system}

Cells of the MPS show a remarkably dynamic nature of the functions they may exert when cultured and investigated in vitro. This is reflected in vivo by the high specialization of tissue macrophages at different anatomical locations (e.g., Langerhans cells in the epidermis, osteoclasts in the bone, microglial cells in the brain, splenic macrophages in the red and white pulp and in the marginal zone of the spleen, and the resident macrophages of the intestinal mucosa [12]). The functional heterogeneity and plasticity of macrophages is already evident in their progenitor cells, the monocytes.

In humans, monocytes are generally divided into two distinct subsets based on their size and granularity and also their differential expression of cell surface receptors (pattern recognition receptors [PRRs], Fc receptors [FcRs], and chemokine receptors). These two main monocyte subsets may exert distinct functions and are believed to represent precursors of distinct macrophage subsets. The so-called inflammatory or classical monocytes are bigger (18 $\mu \mathrm{m}$ in diameter), highly phagocytic, and represent the larger subset $(80-90 \%$ of circulating monocytes in humans). Inflammatory monocytes are $\mathrm{CD} 14^{\mathrm{hi}}, \mathrm{CCR} 1^{+}$, $\mathrm{CCR} 2^{+}, \mathrm{CXCR} 2^{+}$, and $\mathrm{CX} 3 \mathrm{CR} 1^{\text {lo }}$ and are termed "inflammatory" due to their inflammatory chemokine receptor expression pattern. The so-called resident monocytes are smaller (14 $\mu \mathrm{m}$ in diameter) and represent only $10 \%$ of the peripheral blood monocytes. In contrast to the inflammatory monocytes, resident monocytes are generally negative for CD14 and CCR2 but express CD16, CCR5, and CX3CR1 at high levels [23]. The classical (inflammatory) monocytes are believed to migrate chemotactically to sites of inflammation where the production of proinflammatory chemokines such as MCP-1 (CCR2 ligand) and IL8 (CXCR2 ligand) is upregulated. Resident monocytes, on the other hand, are recruited under homeostatic conditions to noninflamed tissues by virtue of their pronounced expression of CX3CR1 [24]. The classification into inflammatory and resident populations is solely based on the different migration behavior of these two subsets under inflammatory and homeostatic conditions. At present, it is not yet entirely clear to what extent this classification also correlates with possible inflammatory vs. resident functional properties of the respective cell populations. As an example, during infections, even the resident-type monocyte subset $\left(\mathrm{CD} 16^{+}\right)$may increase $[25,26]$ and these cells produce substantial amounts of tumor necrosis factor (TNF) upon stimulation with Toll-like receptor (TLR) agonists [27]. Hence, macrophages with a "resident" phenotype may also exert proinflammatory functions. Both resident and inflammatory monocyte subsets can differentiate into DCs in vitro by the addition of IL-4 and GM-CSF [28, 29]. An additional, though smaller, third population of blood monocytes was described in humans. This monocyte subset simultaneously expresses CD14, CD16, and CD64. Because of their high phagocytic activity (shared with the inflammatory subset) and the high expression of major histocompatibility complex (MHC) class II (shared with the resident subset), these cells were called transitional monocytes $[30,31]$.

In the mouse, all circulating monocytes are $\mathrm{CD} 115^{+}$, $\mathrm{CD} 11 \mathrm{~b}^{+}$, and $\mathrm{F} 4 / 80^{\mathrm{lo}}$. Similar to their human counterparts, murine monocytes may be further subdivided into two major subsets, defined mainly by the differential expression of CX3CR1, CD62L, and CCR2. Murine inflammatory monocytes express CCR2, CD62L, and Ly6C at high levels and express CX3CR1 at intermediate levels, while the murine resident monocyte subset is characterized by the high expression of CX3CR1 and the absence of CCR2 and CD62L on the cell surface [20]. In humans as well as in the mouse, inflammatory monocytes appear to be more granular and, with a diameter of 10-14 $\mu \mathrm{m}$, larger than the resident monocytes $(8-12 \mu \mathrm{m})$. Using Ly6C, which shares an epitope with Gr-1, as an additional marker of the inflammatory monocyte subset, Geissmann and collaborators demonstrated that the inflammatory subset $\left(\mathrm{Ly} 6 \mathrm{C}^{+}\right)$ corresponds directly to the human classical $\mathrm{CD} 14^{+}$monocyte subset, thus confirming the conserved relationship of the MPS between humans and mice. While this relevant finding is in full support of using mouse models also for 
defining monocyte/macrophage functions in humans, there are still differences between the mouse and human monocyte/macrophage system as shown in Fig. 2. The ratio of the two main monocyte subsets is generally stable in mice with a small excess of $\mathrm{Ly} 6 \mathrm{C}^{+}$monocytes under homeostatic conditions [32]. Cells of the short-lived inflammatory subset were shown to migrate to sites of experimentally induced inflammation in a CCR2-dependent manner. By virtue of their recognition of MCP-1 (CCL2) and the CD62L-mediated interaction with high endothelial venules, inflammatory monocytes are recruited to the lymph nodes that drain the sites of inflammation [33]. The CCR2-dependent recruitment of inflammatory monocytes is essential for the defense against bacterial ( $L$. monocytogenes) and protozoal (T. gondii) infections [34]. The exit of Ly6 $\mathrm{C}^{+} \mathrm{BM}$ monocytes from the BM may also

\section{HUMAN}

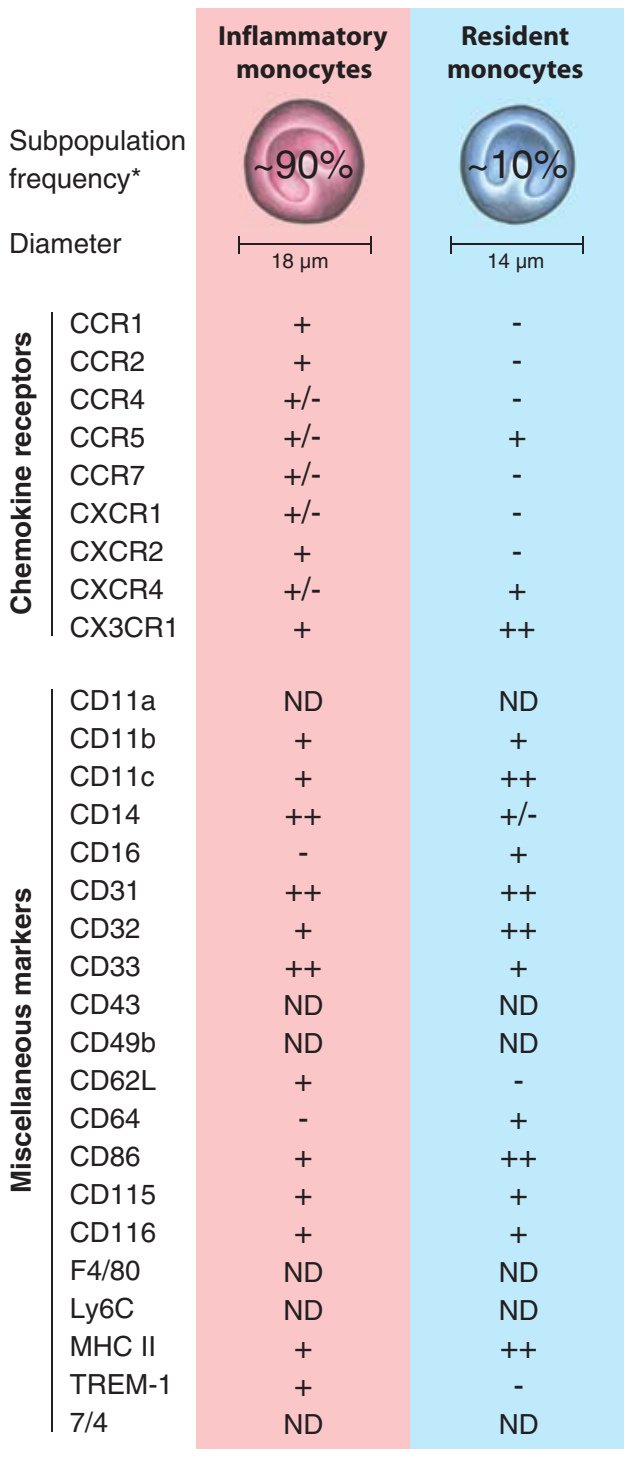

MURINE

\begin{tabular}{|c|c|}
\hline $\begin{array}{c}\text { Inflammatory } \\
\text { monocytes }\end{array}$ & $\begin{array}{c}\text { Resident } \\
\text { monocytes }\end{array}$ \\
\hline $10-14 \mu \mathrm{m}$ & 8-12 $\mu \mathrm{m}$ \\
\hline ND & ND \\
\hline+ & - \\
\hline ND & ND \\
\hline ND & ND \\
\hline ND & ND \\
\hline ND & ND \\
\hline ND & ND \\
\hline+ & $+/-$ \\
\hline++ & + \\
\hline+ & ++ \\
\hline+ & + \\
\hline - & $+/-$ \\
\hline ND & ND \\
\hline$+/-$ & $+/-$ \\
\hline+ & $+/-$ \\
\hline ND & ND \\
\hline ND & ND \\
\hline+ & - \\
\hline+ & - \\
\hline+ & - \\
\hline ND & ND \\
\hline ND & ND \\
\hline+ & + \\
\hline+ & + \\
\hline+ & + \\
\hline++ & $+/-$ \\
\hline - & - \\
\hline - & + \\
\hline+ & - \\
\hline
\end{tabular}

Fig. 2 Frequency and phenotype of the two main circulating monocyte subsets in humans and mice. Human inflammatory monocytes refer to the classical $\mathrm{CD} 14{ }^{\mathrm{hi}} \mathrm{CD} 16^{-}$monocytes (corresponding population in mice: $\mathrm{CX} 3 \mathrm{CR} 1{ }^{\text {lo }} \mathrm{CCR} 2^{+}$), and human resident monocytes refer to the $\mathrm{CD} 14^{10} \mathrm{CD} 16^{+}$monocytes (corresponding population in mice: $\mathrm{CX} 3 \mathrm{CR} 1{ }^{\text {high }} \mathrm{CCR} 2^{-}$). Expression levels of the particular markers are semiquantitatively indicated as minus sign absent, plus/minus sign variable, plus sign positive, double plus sign high expression, and ND not determined. Asterisk frequen- cies of the respective blood monocyte subsets are indicated as percentages relative to the total circulating monocytes. Data are derived from refs. [20, 23, 24, 31-34, 38, 106-111] and the authors' own unpublished data. 7/4 an unidentified mouse antigen recognized by the monoclonal antibody $7 / 4, F 4 / 80$ a monoclonal antibody recognizing the mouse homolog of the human glycoprotein EMR1 (EMRl epidermal growth factor module-containing mucin-like hormone receptor 1) 
depend on CCR2-mediated chemotaxis since $\mathrm{CCR} 2^{-/-}$mice under homeostatic and inflammatory conditions have reduced numbers of circulating inflammatory blood monocytes in the peripheral blood compared to $\mathrm{CCR} 2^{+/+}$mice, while the resident $\mathrm{Ly}_{6} \mathrm{C}^{-}$monocyte subset remains unaltered $[34,35]$. In CX3CR1-GFP transgenic reporter mice [8], circulating monocytes are distinguished based on their differential CX3CR1-GFP expression. The inflammatory monocyte subset is $\mathrm{GFP}^{\mathrm{lo}}$ while resident-type monocytes are $\mathrm{GFP}^{\mathrm{hi}}$. Inflammatory $\mathrm{GFP}^{\text {lo }}$ monocytes upregulate MHC class II and CD11c after migration to the site of inflammation. Thereafter, they move to the draining lymph node where they may further differentiate into DCs [20]. In contrast, the resident $\left(\mathrm{GFP}^{\mathrm{hi}}\right)$ monocytes have a longer life span and, after adoptive transfer, they reconstitute tissue macrophage populations and DCs also under homeostatic conditions [20], while $\mathrm{GFP}^{\text {lo }}$ cells may migrate back to the $\mathrm{BM}$ without entering the peripheral tissues in the absence of inflammation [10] (Fig. 1). Similar to human monocytes, the two main mouse monocyte subsets can differentiate into DCs in vitro in the presence of IL-4 and GM-CSF [20].

One of the central questions of monocyte differentiation is the time and site of differentiation into inflammatory vs. resident monocyte subsets and to which extent monocytes of one subset may later also acquire phenotypic and functional properties of the other subset. In adoptive transfer experiments where both subsets were introduced in recipient mice under homeostatic conditions, inflammatory $\left(\mathrm{Ly} 6 \mathrm{C}^{+}\right)$monocytes disappeared rapidly from the circulation, while the resident monocytes $\left(\right.$ Ly6 $\mathrm{C}^{-}$) persisted. The disappearance of the Ly6 $\mathrm{C}^{+}$inflammatory monocytes was mostly due to a conversion of the inflammatory subset into the resident Ly $6 \mathrm{C}^{-}$subset. Ly $6 \mathrm{C}^{+}$monocytes shuttled back to the BM, converted into Ly $6 \mathrm{C}^{-}$monocytes, and contributed further to the generation of mononuclear phagocytes as residenttype monocytes [10]. A similar downregulation of Ly6C was also observed in in vitro cultures when $\mathrm{Ly} 6 \mathrm{C}^{\text {hi }}$ expressing cells were differentiated into macrophages [3638]. Repopulation studies in mice that were depleted of all circulating monocytes by treatment with clodronateloaded liposomes, revealed in the peripheral blood a population of $\mathrm{Ly} 6 \mathrm{C}^{+}$cells already 3-4 days after depletion, while first $\mathrm{Ly} 6 \mathrm{C}^{-}$monocytes only appeared after more than 1 week after depletion. Together with previous observations that $\mathrm{Ly} 6 \mathrm{C}^{+}$monocytes downregulate Ly6C expression and may convert into $\mathrm{Ly} 6 \mathrm{C}^{-}$monocytes in vivo, this study suggests that the inflammatory Ly $6 \mathrm{C}^{+}$ monocyte subset contains the precursors of the $\mathrm{Ly}_{6} \mathrm{C}^{-}$ resident-type monocytes. During this phenotypic and functional conversion, cells with an intermediate phenotype are detected (approximately $5 \%$ of the circulating monocytes), characterized by the intermediate expression of Ly6C, which may correspond to the $\mathrm{CD} 14^{+}, \mathrm{CD} 16^{+}$, and $\mathrm{CD} 64^{+}$transitional monocytes found in humans [38]. Ly6 $\mathrm{C}^{\text {int }}$ monocytes express a broader spectrum of chemokine receptors and may preferentially migrate to draining lymph nodes due to their expression of CCR7 and CCR8 [39]. The conversion from $\mathrm{Ly} 6 \mathrm{C}^{+}$to $\mathrm{Ly} 6 \mathrm{C}^{-}$monocytes was significantly altered in models of acute (L. monocytogenes) and chronic (L. major) infection, resulting in a significant increase of the immature $\mathrm{Ly} 6 \mathrm{C}^{+}$monocyte population [38]. The correlation of a resident vs. an inflammatory phenotype with a defined functional profile remains poorly characterized also for mouse monocyte subsets. Resident $\left(\mathrm{Ly}_{6} \mathrm{C}^{-}\right.$) blood monocytes were described as cells with a patrolling behavior that allowed them to rapidly invade tissues in case of tissue damage or infection. These $\mathrm{Ly} 6 \mathrm{C}^{-}$cells initiated an early innate immune response at sites of inflammation, mainly by producing TNF, and then differentiated into macrophages [40]. This is in contrast to the inflammatory $\left(\mathrm{Ly}_{6} \mathrm{C}^{+}\right.$) monocytes, which arrive later at sites of infection and show a more DC-like phenotype [41].

The limited insight into the biological and functional properties of distinct monocyte subsets can be attributed to the absence of specific markers to distinguish the various differentiation and also activation stages of the MPS. The phenotypic and functional heterogeneity of the monocyte/macrophage system may be attributed to the remarkably dynamic adaption of macrophage subsets to their microenvironment. This is in part also reflected by the different macrophage subsets that can be generated in vitro with distinct sets of cell-derived and environmental stimuli [21, 22, 42]: Classical activation can be induced by in vitro culture of macrophages with IFN $\gamma$ and LPS. This results in increased antigen presentation, production of proinflammatory cytokines, and an enhanced microbicidal activity. In vitro activation of monocytes in the presence of Th2-type cytokines (IL-4 or IL-13) yields the so-called alternatively activated macrophages characterized by an increased endocytic activity, cell growth, tissue repair, and parasite killing. The culture of monocytes/macrophages in the presence of IL-10 and transforming growth factor- $\beta$ (TGF $\beta$ ) is associated with an anti-inflammatory (or regulatory) phenotype with increased production of IL-10, TGF $\beta$, and $\mathrm{PGE}_{2}$. However, it is still unclear whether corresponding macrophage subsets also exist in vivo and to which extent the differentiation of macrophage lineages is predetermined. It appears likely that in vivo macrophages are exposed to a broad range of soluble and cell surface-expressed mediators that have the potential to activate and differentiate macrophages in a much more elaborate manner than can be mimicked by an in vitro 
culture and, consequently, may result in a highly versatile macrophage phenotype.

\section{The intestine as a major reservoir of macrophages}

The gastrointestinal tract represents the most complex and extensive compartment of the immune system. Due to the sophisticated modifications of the small intestinal mucosa, including folds, villi, and microvilli, the total intestinal surface (in humans) amounts up to $300-400 \mathrm{~m}^{2}$ and the number of colonizing luminal bacteria (up to $10^{14}$ ), representing approximately 1,000 different species, even exceeds the number of cells of the human body [43, 44]. A monolayer consisting of epithelial cells serves as a physical barrier that restricts the penetration of luminal antigens and microbial products and helps to retain the commensal bacteria in the gut lumen. At the same time, the intestinal lamina propria contains an enormous number of immune cells with potent effector functions. About $70 \%$ of all lymphocytes are located within the mucosal immune system, and approximately $10 \%$ of all intestinal lamina propria mononuclear cells are found to be macrophages [45]. The luminal bacterial density increases from the small intestine (SI) to the ileum (distal portion of SI) and the large bowel. Accordingly, intestinal macrophages are most abundant in the colon with slightly lower frequencies in the SI. Hence, the mucosa of the small and the large a Normal colon

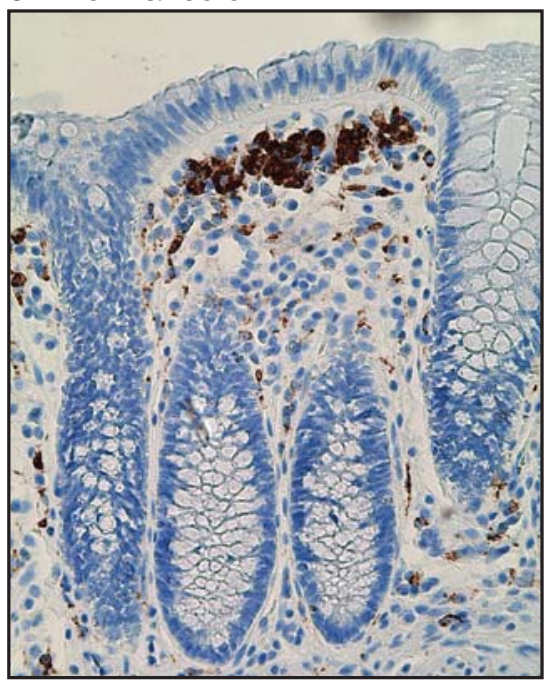

C Ulcerative colitis (UC)

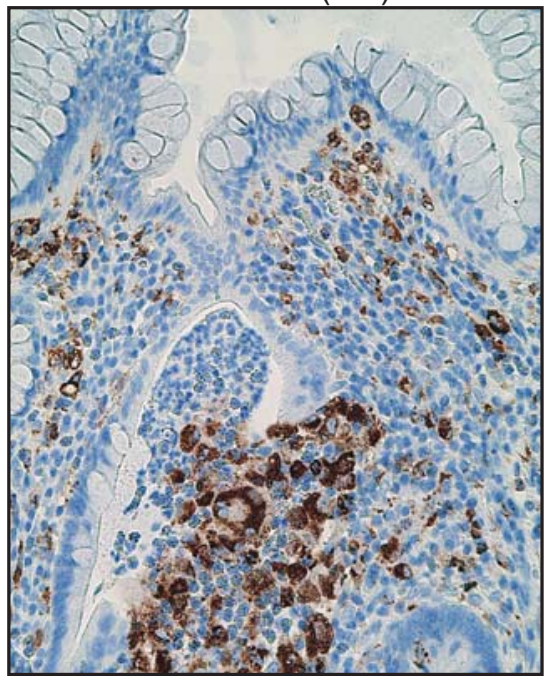

Fig. 3 Immunostaining for the macrophage-specific cytoplasmic protein CD68 on human intestinal tissue sections. Under homeostatic conditions (a, b), most macrophages (brown) are strategically located in the b Normal ileum

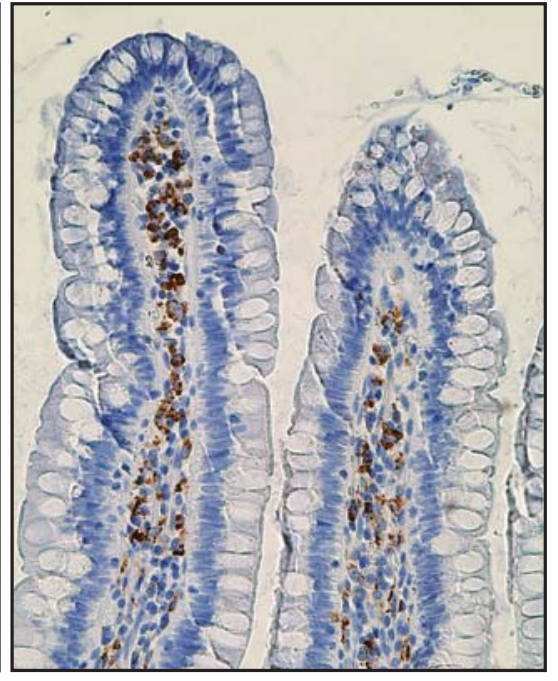

d Crohn's disease (CD)

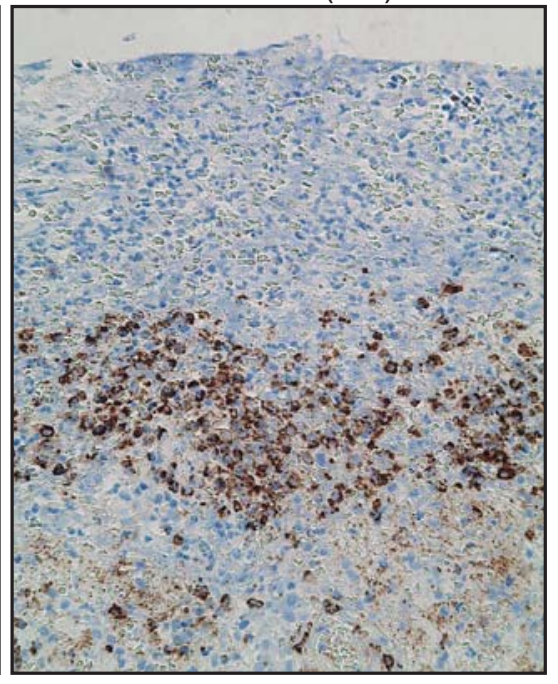

subepithelial mucosa, while during active flares of $\operatorname{IBD}(\mathbf{c}, \mathbf{d})$, the tissue architecture is massively distorted and the numerous macrophages are dispersed in the affected intestinal segments 
intestine represents the largest reservoir of tissue macrophages in humans [45] and mice [46]. Under homeostatic conditions, most of the intestinal macrophages are located in the subepithelial mucosa, i.e., at the preferential site of antigen entry (Fig. 3a, b). At these strategic positions, they are instrumental for the rapid elimination of gut lumenderived bacteria that have breached the epithelial barrier. The highly efficient phagocytic and bactericidal activity of intestinal macrophages prevents the dispersal and proliferation of possibly harmful bacteria. Hence, resident intestinal macrophages exert critical functions for maintaining local tissue homeostasis including the efficient removal of apoptotic cells and foreign debris [47]. Despite the proximity of the large number of intestinal macrophages to the antigen- and bacteria-rich environment, only minimal signs of inflammation are observed in the gut [48]. Under homeostatic conditions, resident intestinal macrophages, together with regulatory $\mathrm{T}$ cells, inhibitory $\mathrm{DCs}$, and possibly even endothelial cells, produce immunomodulatory cytokines that prevent excessive inflammation [49].

\section{Distinct properties of intestinal lamina propria macrophages}

The local tissue microenvironment substantially affects the functional and phenotypic differentiation of tissue macrophages. Hence, during the coevolution of the host immune system with the intestinal flora, the macrophage compartment in the intestine developed several functional adaptations to maintain local tissue homeostasis (Fig. 4). In contrast to their progenitor cells, the resident monocytes, intestinal macrophages do not serve as

Fig. 4 Distinct phenotypic and functional properties of intestinal macrophages and blood monocytes. The presence, or absence, of a particular marker or functional feature is indicated as plus sign and minus sign, respectively. Data are collected from refs. [50-54, 86, 98, 112$114]$ and the authors' own unpublished results. Mø macrophage, Mo monocyte professional antigen-presenting cells (APC) due to their low, or even absent, cell surface expression of CD40, CD80, and CD86 [50]. Intestinal macrophages are deficient in several innate immune recognition mechanisms and activating receptors $[51,52]$ that make them refractory to LPS and other microbe-associated molecular patterns (MAMP), which are present abundantly in the intestinal microflora. They also lack the Fc receptors for IgA (CD89) and for IgG (CD16, CD32, and CD64) [52] and the complement receptors CR3 (CD11b/CD18) and CR4 (CD11c/CD18), and most intestinal macrophages also lack the integrin $\alpha 2 \beta 1$ (LFA-1 and CD11a/CD18) [53]. These $\mathrm{Fc}$ and complement receptors on phagocytes usually mediate cellular activation, secretion of proinflammatory cytokines (such as TNF, IL-1 $\beta$, IL-6, IL-8, and IL-12), and induction of potent adaptive immune responses [53]. These adaptations, however, do not impair the phagocytic activity which is exceptionally potent in intestinal macrophages [53].

Normal intestinal lamina propria macrophages are generally not only refractory to the induction of proinflammatory cytokine production by MAMP (e.g., LPS, or heat-killed $S$. aureus, muramyl dipeptides), but also by cytokines (e.g., TNF, IFN $\gamma$ ), or upon phagocytosis of necrotic cells $[18,53]$. This is in sharp contrast to most other tissue macrophages and blood monocytes. Intestinal macrophages also mostly lack the triggering receptor expressed on myeloid cells-1 (TREM-1), an efficient amplifier of acute and chronic inflammatory reactions that is generally expressed on peripheral blood neutrophils and most monocytes and macrophages of secondary lymphoid organs [54]. Engagement of TREM-1 on TREM-1-positive myeloid cells leads to enhanced secretion of proinflammatory mediators (e.g., TNF, IL-1 $\beta$, MCP-1, IL-6, and IL-8) by monocytes, upregulates several cell surface molecules (e.g., CD40, CD86, and CD32) on monocytes, and prolongs the survival of TREM-1-positive inflammatory cells $[54,55]$.

Such a selective inflammatory anergy of intestinal macrophages in the presence of avid host defense and scavenger functions represents an optimized functional adaptation of these effector cells located in close proximity to the extraordinary load of mostly commensal bacteria-derived, immunostimulatory molecules in the gut lumen. These adaptations efficiently contribute to limiting the dissemination of luminal bacteria to the local mucosa and are also a prerequisite for the tight regulation of the immune responses of the adaptive immune system in the intestinal mucosa. As a further illustration of such a perfect functional adaptation, murine colonic macrophages become triggered to produce large amounts of IL-10 after encountering whole commensal bacteria [56]. 


\section{Regulation of phenotype and functions of intestinal macrophages}

A variety of intestinal cell types including epithelial cells, subepithelial myofibroblasts, fibroblasts, lamina propria lymphocytes, and intraepithelial lymphocytes are all able to produce soluble factors, particularly, TGF $\beta$ and IL-10, which may affect the phenotypic and functional properties of intestinal macrophages [57-60]. The importance of stromal cell-derived factors in shaping the functional capacities of intestinal macrophages is illustrated by the effects induced in blood monocytes upon exposure to intestinal stromal cell-conditioned media. This treatment reduced the expression of several innate response receptors, induced inflammatory anergy, and increased their phagocytic activity, similar to normal intestinal macrophages. These effects were efficiently blocked by anti-TGF $\beta$ antibodies, thus confirming the central role for TGF $\beta$ in this process [53]. IL-10, another relevant immunomodulatory cytokine produced under physiological conditions in the intestinal lamina propria, might also influence the functional properties of intestinal macrophages either by directly dampening monocyte/macrophage functions or indirectly by upregulating TGF $\beta$ production in distinct cell types, including immature DCs and macrophages [61-63]. Intriguingly, monocytes cultured in the presence of recombinant TGF $\beta$ alone or together with IL-10 did not gain an intestinal macrophages-like phenotype such as absence of CD14, whereas IL-10 and TGF $\beta$ synergistically downregulate CD89 and TREM-1 surface expression on blood monocytes and prevented the upregulation of these markers by proinflammatory stimuli such as LPS or TNF [54]. This indicates that, in addition to IL-10 and TGF $\beta$, other intestinal mucosa-derived factors and cognate cell-cell interactions may be required for the full differentiation of recruited monocytes into resident intestinal macrophages. Indications for the additional requirement of cognate interactions between macrophages and intestinal epithelial cells for the complete differentiation into resident intestinal tissue macrophages was indeed obtained in cocultures of monocytes with multicellular spheroids of intestinal epithelial cells. In these in vitro cocultures, the monocytes acquired an intestinal macrophage-like phenotype, characterized by reduced CD14, CD16, CD11b, and CD11c expression and reduced LPS-stimulated IL-1 $\beta$ mRNA expression [64]. This effect, however, was not seen in transwell coculture of monocytes with the same epithelial cells or epithelial cell-conditioned medium and, hence, is likely to require direct cell-cell contacts between macrophages and intestinal epithelial cells [64]. Intestinal lamina propria macrophages are separated from the epithelial cells by the basement membrane [65]. However, subepithelial macrophages may directly interact with intestinal epithelial cells by sending cell protrusions through pores present in the basement membrane [66]. Components of the basement membrane and extracellular matrix were indeed also found to affect macrophage differentiation [67].

The efficient phagocytosis mediated by intestinal lamina propria macrophages should not only be viewed as a mere clearing of potentially harmful agents and dying cells, but may also contribute actively to the establishment of a local immunosuppressive milieu. Phagocytosis of apoptotic cells may induce in macrophages the secretion of immunosuppressive cytokines such as IL-10, whereas the secretion of proinflammatory cytokines such as TNF, IL-12, and IL-1 $\beta$ is significantly reduced [68-70]. Hence, phagocytosis of apoptotic cells may actively alter the functional behavior of intestinal macrophages.

\section{Site-specific differences in the cellular composition of the intestinal mucosa}

The intestinal immune system is the largest and most complex part of the immune system and each compartment of the intestine, from the duodenum to the ileum and the cecum to the rectum, displays distinct regional specializations that may directly affect the functional properties of the local resident immune cells. Most of the intestinal macrophages accumulate beneath the epithelium covering the luminal surface of the lamina propria (Fig. 3a, b). This characteristic distribution pattern is commonly seen at all intestinal sites, including gastric, duodenal, ileal, colonic, and even fetal gastrointestinal mucosa [71]. When compared to macrophages in the deeper lamina propria, subepithelial macrophages display an abundant cytoplasm, containing prominent phagocytosed vesicles or fragments, reminiscent of their high phagocytic activity and efficient elimination of dying cells and foreign particles [72]. Unfortunately, at present, no specific markers are described to further differentiate resident macrophages of the normal intestine in humans and in mice. In particular, in contrast to DC subsets, no differences in the chemokine receptor expression patterns by intestinal macrophages from distinct anatomical sites of the intestinal tract were reported so far.

\section{Macrophage subsets in the normal and inflamed intestinal mucosa}

The intestinal epithelium represents a physical barrier that is far from being tight and, thus, luminal bacteria may breach the epithelial barrier to get access to the subepithelial lamina propria. These invading commensal bacteria are rapidly phagocytosed by the lamina propria macrophages, 
which are strategically located underneath the epithelium. This is most obvious in the large intestine where the concentration of luminal bacteria is several orders of magnitude higher than in the SI and where highest frequencies of subepithelial macrophages are seen (Fig. 3a, b). The importance of the functional adaptations of the local intestinal immune system to its unique environment is best illustrated during failure of these mechanisms, e.g., during the development of chronic intestinal inflammation, either in patients with celiac disease, inflammatory bowel diseases (IBD), or in various mouse strains deficient for genes involved in the control of immune responses such as IL-10 and TGF $\beta$ [73-76]. Deregulated immune response(s) against an otherwise harmless luminal microflora in susceptible individuals is now generally recognized as a key factor in the pathogenesis of IBD.

\section{Celiac disease}

Celiac disease, or celiac sprue, is a malabsorption syndrome which is initiated in genetically predisposed persons by the ingestion of gluten, a major protein of wheat and related cereals. The disease is triggered by exposure to gliadin peptides, which are derived from protease-digested gluten and are transported across the intestinal epithelial barrier to the lamina propria where they are deamidated by the enzyme tissue transglutaminase (tTG). These deamidated, gliadin-derived neoantigens are preferentially presented by HLA-DQ2 or HLA-DQ8 molecules to pathogenic CD4 $\mathrm{T}$ cells in the lamina propria [77]. Histologically, the affected small intestinal mucosa in florid celiac disease reveals a hyperplasia of the crypt cells, a hypercellularity of the lamina propria with locally increased numbers of CD4 T cells and plasma cells, together with an atrophy of the villi, leading to a complete flattening of the mucosa. These morphological changes are generally reversible during a gluten-free diet. Intestinal intraepithelial lymphocytes are typically increased in florid celiac disease and particularly TCR $\gamma \delta \mathrm{T}$ cells are overrepresented in the affected small intestinal epithelium. The interaction of the activating receptor NKG2D on a subset of small intestinal TCR $\gamma \delta \mathrm{T}$ cells with the cognate NKG2D ligand on enterocytes, i.e., the class Ib molecules MICA/B, can induce cytotoxic effector functions in subsets of TCR $\gamma \delta$ T cells and CD 8 TCR $\alpha \beta$ T cells, thus, contributing to the characteristic villous atrophy in patients with florid celiac disease $[78,79]$. In addition to these lymphocytemediated effects, a disease-exacerbating role has been also ascribed to macrophages in response to the enhanced presence of gliadin in the small intestinal mucosa: Gliadin-derived peptides reportedly directly stimulated peritoneal macrophages for an enhanced secretion of cytokines including TNF and the monocyte recruiting chemokine CCL5 [80]. In an in vitro system, gliadin also enhanced the epithelial permeability and a MyD88dependent increased synthesis of IL-12 and TNF in primary mouse macrophages [81].

\section{Inflammatory bowel diseases}

IBD cover two major clinical entities, i.e., ulcerative colitis (UC) and Crohn's disease (CD). In UC, the inflammatory process is restricted to the mucosa of the large bowel and only in the most active stages of the disease may lead to ulcerations. Excessive inflammation in $\mathrm{CD}$ may involve any part of the gastrointestinal tract with the SI and/or the colon being most often affected. In $\mathrm{CD}$, all layers may be involved by the inflammatory reaction and fissures and fistula formation are a severe complication of active disease. In CD, segments of macroscopically normal bowel may be present between affected bowel segments ("skip lesions"). The breakdown of oral tolerance, i.e., loss of attenuated $\mathrm{T}$ cell responses against the indigenous flora, may initiate IBD in genetically susceptible individuals and can result from alteration(s) in signaling pathways of PRRs, as it is likely the case for mutations in the NOD2/CARD15 locus that represents a susceptibility locus for CD [82-84]. Therefore, deregulated MAMP signaling and the resulting defects in APCs function or in APC-T cell interactions may lead to deregulated $\mathrm{T}$ cell responses. Hence, aberrant activation and functions of intestinal macrophages are also likely to contribute to chronic intestinal inflammation.

In the inflamed intestinal mucosa of patients with active IBD, the numbers of macrophages are increased (Fig. 3c, d). Some of these macrophages display a different phenotypic and functional profile than under physiological conditions. In contrast to the characteristic antiinflammatory phenotypic and functional profile of normal intestinal lamina propria macrophages, at sites of mucosal inflammation, macrophages express relevant levels of $\mathrm{T}$ cell costimulatory molecules such as CD40, CD80, and CD86 [50]. Furthermore, subsets of intestinal macrophages express PRRs such as TLR2 and TLR4 at the site of intestinal inflammation. These inflammatory macrophages often coexpress CD14, CD89, and TREM-1 [18, 51, 85-87]. In these inflammatory conditions, the close proximity of subepithelial macrophages to the intestinal flora thus results in a constant, excessive activation of the mucosal innate immune system and monocytes recruited during inflammatory conditions likely fail to acquire the tightly regulated and adapted intestinal macrophage phenotype. Consequently, they may react to luminal antigens, function as potent effector cells, exert high antigen-presenting capability, and 
become potent producers of proinflammatory cytokine [51]. Since both costimulatory molecules and "danger signals" are present, these macrophages trigger the adaptive immune system to react against luminal antigens. Under inflammatory conditions, the epithelial barrier function is usually disturbed and, as a result, the influx of luminal microbes and microbial products to the lamina propria is increased. This further enhances the activation and recruitment of additional inflammatory cells to sustain the inflammatory process. The DAP-12-associated activating receptor TREM-1 triggers the synthesis and secretion of proinflammatory cytokines, and consequently, the local tissue destruction. In the affected areas of patients with active UC or CD, TREM-1-expressing macrophages are significantly increased when compared to normal intestinal tissues. Engagement of TREM-1 on positive macrophages in patients with active IBD leads to a significant, severalfold increased secretion of TNF and other proinflammatory mediators such as IL-1 $\beta$, MCP-1, IL-6, and IL-8 [87]. Hence, deregulated macrophage functions at distinct levels likely contribute to the development and perpetuation of intestinal inflammation characteristically seen in patients with IBD [88].

The relevance of appropriate macrophage regulation for maintaining local tissue homeostasis in the gut has been also nicely demonstrated in mouse models. As an example, selective disruption of Stat 3 signaling in macrophages leads to severely impaired production of IL-10 and consequently leads to the spontaneous development of colitis [89]. Similarly, IL- $10^{-/-}$mice spontaneously develop colitis as a consequence of the preferential macrophage differentiation into proinflammatory subsets that produce large amounts of IL-12 and IL-23. Remarkably, the depletion of macrophages in these IL- $10^{-/-}$mice prevents the development of colitis [56].

Several observations in patients provided additional, circumstantial evidence for a central participation of macrophages in the pathogenesis of IBD. As an example, recurrent infections with pathogens that directly target the macrophages (e.g. M. paratuberculosis, M. avium, or paramyxoviruses) were repeatedly reported in patients with IBD. Therefore, deregulated or aberrant responses of macrophages in patients with IBD to these intracellular pathogens may be involved in the disease process. This notion is further supported by the molecular characterization of the first IBD susceptibility locus (ibd1), i.e., NOD2/ CARD15, which is also expressed in monocytes and macrophages [82, 83] and reacts with the bacterial component muramyl dipeptide $[90,91]$. The mutant form of NOD2 (3020insC), associated with CD, does not appear to respond to muramyl dipeptide-mediated stimulation [9194]. At present, it is still controversial whether NOD2 is a positive, or negative, regulator of TLR2-mediated responses that may be impaired in the presence of the mutated NOD2 [95-97]. Remarkably, another recently characterized IBD susceptibility locus is the receptor for IL-23, a proinflammatory cytokine produced predominantly by cells of the monocyte/macrophage lineage. Intriguingly, in patients with active $\mathrm{CD}$, but not in patients with UC, intestinal macrophages produced significantly more IL-23 than intestinal macrophages from noninflamed mucosa. The enhanced production of IL-23 by intestinal macrophages from patients with $\mathrm{CD}$ upon in vitro culture was dependent on local IFN $\gamma$ secretion and was further increased in the presence of commensal bacteria (E. coli, E. faecalis). In contrast to the production of IL-23, which was induced only in lamina propria macrophages from $\mathrm{CD}$ patients, mRNA expression and production of IL- 6 was increased in lamina propria macrophages from both $\mathrm{UC}$ and $\mathrm{CD}$ patients when compared with macrophages obtained from noninflamed intestinal lamina propria of control patients [98].

The importance of macrophages in the pathogenesis of IBD is supported by reports identifying macrophages as the main source of TNF during the pathogenesis of IBD and the beneficial effects of anti-TNF treatments in patients with CD. The striking effects of this TNF-targeted therapy may in IBD also be attributed to the cell-depleting effect of some of these therapies, including the removal of TNFexpressing monocytes/macrophages [99]. TNF produced by nonlymphoid cells (mostly macrophages) is essential for colitis in an adoptive $\mathrm{T}$ cell model of colitis induction in lymphopenic recipients. Intriguingly, in this mouse model, TNF production by the transferred CD4 $\mathrm{T}$ cells was not required, nor sufficient, for disease induction when nonlymphoid cells, i.e., mostly macrophages, produced TNF in the affected intestinal mucosa [100].

\section{Conclusions}

Until recently, the research on the etiopathogenetic role of intestinal immunopathological disorders such as celiac disease and IBD mostly focused on effector mechanisms of the adaptive immune system such as pathogenic and regulatory $\mathrm{T}$ cell subsets, whereas the innate immune system had received relatively little attention. However, the past few years witnessed several important advances that indicated a central role for cells of the innate immune system in the pathogenesis of these disorders. The relevance of intestinal macrophages in the pathogenesis of IBD is highlighted by their functions as gatekeepers, driving adaptive immune responses to either tolerance induction or initiation of inflammatory reactions. Elucidation of the detailed mechanisms of how local macrophages and/or blood monocytes functionally differentiate and 
participate in the pathogenesis of various inflammatory disorders may allow designing specific strategies to target the induction of deregulated adaptive immune responses and excessive inflammation. Detailed knowledge about monocytes/macrophage lineage relationships, differential homing capacities, and the plasticity of these cell subsets is crucial to design rational strategies to interfere with their involvement in excessive immunopathological reactions, including chronic inflammatory disorders of the gastrointestinal tract.

Acknowledgements The authors would like to thank Ursula Yela for the assistance during the preparation of the manuscript and Jasmin Ossola for the assistance with the preparation of the figures. The present work of the authors is supported by grants of the Swiss National Science Foundation and the 3R Foundation to CM.

\section{References}

1. Gordon S (2007) The macrophage: past, present and future. Eur J Immunol 37(Suppl 1):S9-S17. doi:10.1002/eji.200737638

2. Pollard JW (2009) Trophic macrophages in development and disease. Nat Rev Immunol 9:259-270. doi:10.1038/nri2528

3. Hume DA (2008) Differentiation and heterogeneity in the mononuclear phagocyte system. Mucosal Immunol 1:432-441

4. Iwasaki H, Akashi K (2007) Myeloid lineage commitment from the hematopoietic stem cell. Immunity 26:726-740. doi:10.1016/ j.immuni.2007.06.004

5. Spangrude GJ, Heimfeld S, Weissman IL (1988) Purification and characterization of mouse hematopoietic stem cells. Science 241:58-62. doi:10.1126/science.2898810

6. Akashi K, Traver D, Miyamoto T, Weissman IL (2000) A clonogenic common myeloid progenitor that gives rise to all myeloid lineages. Nature 404:193-197. doi:10.1038/35004599

7. Kondo M, Weissman IL, Akashi K (1997) Identification of clonogenic common lymphoid progenitors in mouse bone marrow. Cell 91:661-672. doi:10.1016/S0092-8674(00) 80453-5

8. Jung S, Aliberti J, Graemmel P, Sunshine MJ, Kreutzberg GW, Sher A, Littman DR (2000) Analysis of fractalkine receptor CX (3) CR1 function by targeted deletion and green fluorescent protein reporter gene insertion. Mol Cell Biol 20:4106-4114. doi:10.1128/MCB.20.11.4106-4114.2000

9. Fogg DK, Sibon C, Miled C, Jung S, Aucouturier P, Littman DR, Cumano A, Geissmann F (2006) A clonogenic bone marrow progenitor specific for macrophages and dendritic cells. Science 311:83-87. doi:10.1126/science.1117729

10. Varol C, Landsman L, Fogg DK, Greenshtein L, Gildor B, Margalit R, Kalchenko V, Geissmann F, Jung S (2007) Monocytes give rise to mucosal, but not splenic, conventional dendritic cells. J Exp Med 204:171-180. doi:10.1084/ jem.20061011

11. Gendelman HE, Orenstein JM, Martin MA, Ferrua C, Mitra R, Phipps T, Wahl LA, Lane HC, Fauci AS, Burke DS et al (1988) Efficient isolation and propagation of human immunodeficiency virus on recombinant colony-stimulating factor 1treated monocytes. J Exp Med 167:1428-1441. doi:10.1084/ jem.167.4.1428

12. Gordon S, Taylor PR (2005) Monocyte and macrophage heterogeneity. Nat Rev Immunol 5:953-964. doi:10.1038/ nri1733
13. Crofton RW, Diesselhoff-den Dulk MM, van Furth R (1978) The origin, kinetics, and characteristics of the Kupffer cells in the normal steady state. J Exp Med 148:1-17. doi:10.1084/ jem.148.1.1

14. Hickey WF (1999) The pathology of multiple sclerosis: a historical perspective. J Neuroimmunol 98:37-44. doi:10.1016/ S0165-5728(99)00079-X

15. Merad M, Manz MG, Karsunky H, Wagers A, Peters W, Charo I, Weissman IL, Cyster JG, Engleman EG (2002) Langerhans cells renew in the skin throughout life under steady-state conditions. Nat Immunol 3:1135-1141. doi:10.1038/ni852

16. Tarling JD, Lin HS, Hsu S (1987) Self-renewal of pulmonary alveolar macrophages: evidence from radiation chimera studies. J Leukoc Biol 42:443-446

17. Sawyer RT, Strausbauch PH, Volkman A (1982) Resident macrophage proliferation in mice depleted of blood monocytes by strontium-89. Lab Invest 46:165-170

18. Smith PD, Ochsenbauer-Jambor C, Smythies LE (2005) Intestinal macrophages: unique effector cells of the innate immune system. Immunol Rev 206:149-159. doi:10.1111/j.0105-2896.2005.00288.x

19. Xaus J, Cardo M, Valledor AF, Soler C, Lloberas J, Celada A (1999) Interferon gamma induces the expression of p21waf-1 and arrests macrophage cell cycle, preventing induction of apoptosis. Immunity 11:103-113. doi:10.1016/S1074-7613(00) 80085-0

20. Geissmann F, Jung S, Littman DR (2003) Blood monocytes consist of two principal subsets with distinct migratory properties. Immunity 19:71-82

21. Gordon S (2003) Alternative activation of macrophages. Nat Rev Immunol 3:23-35. doi:10.1038/nri978

22. Mosser DM, Edwards JP (2008) Exploring the full spectrum of macrophage activation. Nat Rev Immunol 8:958-969. doi:10.1038/nri2448

23. Passlick B, Flieger D, Ziegler-Heitbrock HW (1989) Identification and characterization of a novel monocyte subpopulation in human peripheral blood. Blood 74:2527-2534

24. Ancuta P, Rao R, Moses A, Mehle A, Shaw SK, Luscinskas FW, Gabuzda D (2003) Fractalkine preferentially mediates arrest and migration of CD16+ monocytes. J Exp Med 197:1701-1707. doi:10.1084/jem.20022156

25. Thieblemont N, Weiss L, Sadeghi HM, Estcourt C, HaeffnerCavaillon N (1995) CD14lowCD16high: a cytokine-producing monocyte subset which expands during human immunodeficiency virus infection. Eur J Immunol 25:3418-3424. doi:10.1002/ eji. 1830251232

26. Fingerle G, Pforte A, Passlick B, Blumenstein M, Strobel M, Ziegler-Heitbrock HW (1993) The novel subset of CD14+/CD16 + blood monocytes is expanded in sepsis patients. Blood 82:3170-3176

27. Belge KU, Dayyani F, Horelt A, Siedlar M, Frankenberger M, Frankenberger B, Espevik T, Ziegler-Heitbrock L (2002) The proinflammatory $\mathrm{CD} 14+\mathrm{CD} 16+\mathrm{DR}++$ monocytes are a major source of TNF. J Immunol 168:3536-3542

28. Sanchez-Torres C, Garcia-Romo GS, Cornejo-Cortes MA, Rivas-Carvalho A, Sanchez-Schmitz G (2001) CD16+ and CD16- human blood monocyte subsets differentiate in vitro to dendritic cells with different abilities to stimulate CD4+ T cells. Int Immunol 13:1571-1581. doi:10.1093/intimm/13.12.1571

29. Sallusto F, Lanzavecchia A (1994) Efficient presentation of soluble antigen by cultured human dendritic cells is maintained by granulocyte/macrophage colony-stimulating factor plus interleukin 4 and downregulated by tumor necrosis factor alpha. J Exp Med 179:1109-1118. doi:10.1084/jem.179.4.1109

30. Grage-Griebenow E, Flad HD, Ernst M, Bzowska M, Skrzeczynska J, Pryjma J (2000) Human MO subsets as defined by expression of CD64 and CD16 differ in phagocytic 
activity and generation of oxygen intermediates. Immunobiology $202: 42-50$

31. Grage-Griebenow E, Zawatzky R, Kahlert H, Brade L, Flad H, Ernst M (2001) Identification of a novel dendritic cell-like subset of CD64(+)/CD16(+) blood monocytes. Eur J Immunol 31:48-56. doi:10.1002/1521-4141(200101)31:1<48::AID-IMMU48>3.0. $\mathrm{CO} ; 2-5$

32. Landsman L, Bar-On L, Zernecke A, Kim KW, Krauthgamer R, Shagdarsuren E, Lira SA, Weissman IL, Weber C, Jung S (2009) CX3CR1 is required for monocyte homeostasis and atherogenesis by promoting cell survival. Blood 113:963-972. doi:10.1182/blood-2008-07-170787

33. Palframan RT, Jung S, Cheng G, Weninger W, Luo Y, Dorf M, Littman DR, Rollins BJ, Zweerink H, Rot A, von Andrian UH (2001) Inflammatory chemokine transport and presentation in HEV: a remote control mechanism for monocyte recruitment to lymph nodes in inflamed tissues. J Exp Med 194:1361-1373. doi:10.1084/jem.194.9.1361

34. Serbina NV, Jia T, Hohl TM, Pamer EG (2008) Monocytemediated defense against microbial pathogens. Annu Rev Immunol 26:421-452. doi:10.1146/annurev.immunol.26. 021607.090326

35. Tsou CL, Peters W, Si Y, Slaymaker S, Aslanian AM, Weisberg SP, Mack M, Charo IF (2007) Critical roles for CCR2 and MCP3 in monocyte mobilization from bone marrow and recruitment to inflammatory sites. J Clin Invest 117:902-909. doi:10.1172/ JC129919

36. de Bruijn MF, Slieker WA, van der Loo JC, Voerman JS, van Ewijk W, Leenen PJ (1994) Distinct mouse bone marrow macrophage precursors identified by differential expression of ER-MP12 and ER-MP20 antigens. Eur J Immunol 24:22792284. doi:10.1002/eji.1830241003

37. Nikolic T, de Bruijn MF, Lutz MB, Leenen PJ (2003) Developmental stages of myeloid dendritic cells in mouse bone marrow. Int Immunol 15:515-524. doi:10.1093/intimm/ dxg050

38. Sunderkoetter C, Nikolic T, Dillon MJ, Van Rooijen N, Stehling M, Drevets DA, Leenen PJ (2004) Subpopulations of mouse blood monocytes differ in maturation stage and inflammatory response. J Immunol 172:4410-4417

39. Qu C, Edwards EW, Tacke F, Angeli V, Llodra J, SanchezSchmitz G, Garin A, Haque NS, Peters W, van Rooijen N, Sanchez-Torres C, Bromberg J, Charo IF, Jung S, Lira SA, Randolph GJ (2004) Role of CCR8 and other chemokine pathways in the migration of monocyte-derived dendritic cells to lymph nodes. J Exp Med 200:1231-1241. doi:10.1084/ jem.20032152

40. Auffray C, Fogg D, Garfa M, Elain G, Join-Lambert O, Kayal S, Sarnacki S, Cumano A, Lauvau G, Geissmann F (2007) Monitoring of blood vessels and tissues by a population of monocytes with patrolling behavior. Science 317:666-670. doi:10.1126/science.1142883

41. Serbina NV, Salazar-Mather TP, Biron CA, Kuziel WA, Pamer EG (2003) TNF/iNOS-producing dendritic cells mediate innate immune defense against bacterial infection. Immunity 19:59-70. doi:10.1016/S1074-7613(03)00171-7

42. Taylor PR, Martinez-Pomares L, Stacey M, Lin HH, Brown GD, Gordon S (2005) Macrophage receptors and immune recognition. Annu Rev Immunol 23:901-944. doi:10.1146/annurev. immunol.23.021704.115816

43. Schenk M, Mueller C (2008) The mucosal immune system at the gastrointestinal barrier. Best Pract Res Clin Gastroenterol 22:391-409. doi:10.1016/j.bpg.2007.11.002

44. Macpherson AJ, Harris NL (2004) Interactions between commensal intestinal bacteria and the immune system. Nat Rev Immunol 4:478-485. doi:10.1038/nri1373
45. Bull DM, Bookman MA (1977) Isolation and functional characterization of human intestinal mucosal lymphoid cells. J Clin Invest 59:966-974. doi:10.1172/JCI108719

46. Lee SH, Starkey PM, Gordon S (1985) Quantitative analysis of total macrophage content in adult mouse tissues. Immunochemical studies with monoclonal antibody F4/80. J Exp Med 161:475-489. doi:10.1084/jem.161.3.475

47. Schenk M, Mueller C (2007) Adaptations of intestinal macrophages to an antigen-rich environment. Semin Immunol 19:8493

48. Kanai $T$, Ilyama $R$, Ishikura $T$, Uraushihara $K$, Totsuka $T$, Yamazaki M, Nakamuma T, Watanabe M (2002) Role of the innate immune system in the development of chronic colitis. J Gastroenterol 37(Suppl 14):38-42

49. Platt AM, Mowat AM (2008) Mucosal macrophages and the regulation of immune responses in the intestine. Immunol Lett 119:22-31. doi:10.1016/j.imlet.2008.05.009

50. Rugtveit J, Bakka A, Brandtzaeg P (1997) Differential distribution of B7.1 (CD80) and B7.2 (CD86) costimulatory molecules on mucosal macrophage subsets in human inflammatory bowel disease (IBD). Clin Exp Immunol 110:104-113. doi:10.1111/ j.1365-2249.1997.507-ce1404.x

51. Hausmann M, Kiessling S, Mestermann S, Webb G, Spottl T, Andus T, Scholmerich J, Herfarth H, Ray K, Falk W, Rogler G (2002) Toll-like receptors 2 and 4 are up-regulated during intestinal inflammation. Gastroenterology 122:1987-2000. doi:10.1053/gast.2002.33662

52. Smith PD, Smythies LE, Mosteller-Barnum M, Sibley DA, Russell MW, Merger M, Sellers MT, Orenstein JM, Shimada T, Graham MF, Kubagawa H (2001) Intestinal macrophages lack CD14 and CD89 and consequently are down-regulated for LPS- and IgA-mediated activities. J Immunol 167:26512656

53. Smythies LE, Sellers M, Clements RH, Mosteller-Barnum M, Meng G, Benjamin WH, Orenstein JM, Smith PD (2005) Human intestinal macrophages display profound inflammatory anergy despite avid phagocytic and bacteriocidal activity. J Clin Invest 115:66-75

54. Schenk M, Bouchon A, Birrer S, Colonna M, Mueller C (2005) Macrophages expressing triggering receptor expressed on myeloid cells-1 are underrepresented in the human intestine. J Immunol 174:517-524

55. Bouchon A, Dietrich J, Colonna M (2000) Cutting edge: inflammatory responses can be triggered by TREM-1, a novel receptor expressed on neutrophils and monocytes. J Immunol 164:4991-4995

56. Kamada N, Hisamatsu T, Okamoto S, Sato T, Matsuoka K, Arai $\mathrm{K}$, Nakai T, Hasegawa A, Inoue N, Watanabe N, Akagawa KS, Hibi T (2005) Abnormally differentiated subsets of intestinal macrophage play a key role in Th1-dominant chronic colitis through excess production of IL-12 and IL-23 in response to bacteria. J Immunol 175:6900-6908

57. Maloy KJ, Powrie F (2001) Regulatory T cells in the control of immune pathology. Nat Immunol 2:816-822. doi:10.1038/ ni0901-816

58. Maloy KJ, Salaun L, Cahill R, Dougan G, Saunders NJ, Powrie F (2003) CD4+CD25+ T(R) cells suppress innate immune pathology through cytokine-dependent mechanisms. J Exp Med 197:111-119. doi:10.1084/jem.20021345

59. Xian CJ, Mardell CE, Read LC (1999) Specificity of the localization of transforming growth factor-alpha immunoreactivity in colon mucosa. J Histochem Cytochem 47:949-958

60. Khoo UY, Proctor IE, Macpherson AJ (1997) CD4+ T cell down-regulation in human intestinal mucosa: evidence for intestinal tolerance to luminal bacterial antigens. J Immunol $158: 3626-3634$ 
61. Moore KW, O'Garra A, de Waal Malefyt R, Vieira P, Mosmann TR (1993) Interleukin-10. Annu Rev Immunol 11:165-190. doi:10.1146/annurev.iy.11.040193.001121

62. Stordeur P, Goldman M (1998) Interleukin-10 as a regulatory cytokine induced by cellular stress: molecular aspects. Int Rev Immunol 16:501-522. doi:10.3109/08830189809043006

63. Cassatella MA, Meda L, Gasperini S, Calzetti F, Bonora S (1994) Interleukin 10 (IL-10) upregulates IL-1 receptor antagonist production from lipopolysaccharide-stimulated human polymorphonuclear leukocytes by delaying mRNA degradation. J Exp Med 179:1695-1699. doi:10.1084/ jem.179.5.1695

64. Rogler G, Gelbmann CM, Vogl D, Brunner M, Scholmerich J, Falk W, Andus T, Brand K (2001) Differential activation of cytokine secretion in primary human colonic fibroblast/myofibroblast cultures. Scand J Gastroenterol 36:389-398. doi: $10.1080 / 003655201300051216$

65. Pavli P, Gibson PR (1992) Pathogenic factors in inflammatory bowel disease. 2. Crohn's disease. Dig Dis 10:72-84. doi: $10.1159 / 000171346$

66. Takahashi-Iwanaga H, Iwanaga T, Isayama H (1999) Porosity of the epithelial basement membrane as an indicator of macrophage-enterocyte interaction in the intestinal mucosa. Arch Histol Cytol 62:471-481. doi:10.1679/aohc.62.471

67. Hohn HP, Grummer R, Bosserhoff S, Graf-Lingnau S, Reuss B, Backer C, Denker HW (1996) The role of matrix contact and of cell-cell interactions in choriocarcinoma cell differentiation. Eur J Cell Biol 69:76-85

68. Fadok VA, Bratton DL, Konowal A, Freed PW, Westcott JY, Henson PM (1998) Macrophages that have ingested apoptotic cells in vitro inhibit proinflammatory cytokine production through autocrine/paracrine mechanisms involving TGF-beta, PGE2, and PAF. J Clin Invest 101:890-898. doi:10.1172/ JCI1112

69. Zhang WJ, Zheng SS (2005) In vitro study of immunosuppressive effect of apoptotic cells. J Zhejiang Univ Sci B 6:919-925. doi:10.1631/jzus.2005.B0919

70. Kurosaka K, Watanabe N, Kobayashi Y (2002) Potentiation by human serum of anti-inflammatory cytokine production by human macrophages in response to apoptotic cells. J Leukoc Biol 71:950-956

71. Nadeau KC, Azuma H, Tilney NL (1995) Sequential cytokine dynamics in chronic rejection of rat renal allografts: roles for cytokines RANTES and MCP-1. Proc Natl Acad Sci U S A 92:8729-8733. doi:10.1073/pnas.92.19.8729

72. Nagashima R, Maeda K, Imai Y, Takahashi T (1996) Lamina propria macrophages in the human gastrointestinal mucosa: their distribution, immunohistological phenotype, and function. J Histochem Cytochem 44:721-731

73. Madsen KL, Doyle JS, Tavernini MM, Jewell LD, Rennie RP, Fedorak RN (2000) Antibiotic therapy attenuates colitis in interleukin 10 gene-deficient mice. Gastroenterology 118:10941105. doi:10.1016/S0016-5085(00)70362-3

74. Kuhn R, Lohler J, Rennick D, Rajewsky K, Muller W (1993) Interleukin-10-deficient mice develop chronic enterocolitis. Cell 75:263-274. doi:10.1016/0092-8674(93)80068-P

75. Hahm KB, Im YH, Parks TW, Park SH, Markowitz S, Jung HY, Green J, Kim SJ (2001) Loss of transforming growth factor beta signalling in the intestine contributes to tissue injury in inflammatory bowel disease. Gut 49:190-198. doi:10.1136/ gut.49.2.190

76. Shull MM, Ormsby I, Kier AB, Pawlowski S, Diebold RJ, Yin M, Allen R, Sidman C, Proetzel G, Calvin D et al (1992) Targeted disruption of the mouse transforming growth factorbeta 1 gene results in multifocal inflammatory disease. Nature 359:693-699. doi:10.1038/359693a 0
77. Green PH, Cellier C (2007) Celiac disease. N Engl J Med 357:1731-1743. doi:10.1056/NEJMra071600

78. Meresse B, Chen Z, Ciszewski C, Tretiakova M, Bhagat G, Krausz TN, Raulet DH, Lanier LL, Groh V, Spies T, Ebert EC, Green PH, Jabri B (2004) Coordinated induction by IL15 of a TCR-independent NKG2D signaling pathway converts CTL into lymphokine-activated killer cells in celiac disease. Immunity 21:357-366. doi:10.1016/j.immuni.2004.06.020

79. Hue S, Mention JJ, Monteiro RC, Zhang S, Cellier C, Schmitz J, Verkarre V, Fodil N, Bahram S, Cerf-Bensussan N, CaillatZucman S (2004) A direct role for NKG2D/MICA interaction in villous atrophy during celiac disease. Immunity 21:367-377. doi:10.1016/j.immuni.2004.06.018

80. Tuckova L, Novotna J, Novak P, Flegelova Z, Kveton T, Jelinkova L, Zidek Z, Man P, Tlaskalova-Hogenova H (2002) Activation of macrophages by gliadin fragments: isolation and characterization of active peptide. J Leukoc Biol 71:625-631

81. Thomas KE, Sapone A, Fasano A, Vogel SN (2006) Gliadin stimulation of murine macrophage inflammatory gene expression and intestinal permeability are MyD88-dependent: role of the innate immune response in Celiac disease. J Immunol 176:25122521

82. Hugot JP, Chamaillard M, Zouali H, Lesage S, Cezard JP, Belaiche J, Almer S, Tysk C, O'Morain CA, Gassull M, Binder V, Finkel Y, Cortot A, Modigliani R, Laurent-Puig P, GowerRousseau C, Macry J, Colombel JF, Sahbatou M, Thomas G (2001) Association of NOD2 leucine-rich repeat variants with susceptibility to Crohn's disease. Nature 411:599-603. doi:10.1038/35079107

83. Ogura Y, Bonen DK, Inohara N, Nicolae DL, Chen FF, Ramos R, Britton H, Moran T, Karaliuskas R, Duerr RH, Achkar JP, Brant SR, Bayless TM, Kirschner BS, Hanauer SB, Nunez G, Cho JH (2001) A frameshift mutation in NOD2 associated with susceptibility to Crohn's disease. Nature 411:603-606. doi:10.1038/35079114

84. Hampe J, Cuthbert A, Croucher PJ, Mirza MM, Mascheretti S, Fisher S, Frenzel H, King K, Hasselmeyer A, MacPherson AJ, Bridger S, van Deventer S, Forbes A, Nikolaus S, Lennard-Jones JE, Foelsch UR, Krawczak M, Lewis C, Schreiber S, Mathew CG (2001) Association between insertion mutation in NOD2 gene and Crohn's disease in German and British populations. Lancet 357:1925-1928. doi:10.1016/ S0140-6736(00)05063-7

85. Rogler G, Andus T, Aschenbrenner E, Vogl D, Falk W, Scholmerich J, Gross V (1997) Alterations of the phenotype of colonic macrophages in inflammatory bowel disease. Eur $\mathrm{J}$ Gastroenterol Hepatol 9:893-899

86. Smith PD, Janoff EN, Mosteller-Barnum M, Merger M, Orenstein JM, Kearney JF, Graham MF (1997) Isolation and purification of CD14-negative mucosal macrophages from normal human small intestine. J Immunol Methods 202:1-11. doi:10.1016/S0022-1759(96)00204-9

87. Schenk M, Bouchon A, Seibold F, Mueller C (2007) TREM-1expressing intestinal macrophages crucially amplify chronic inflammation in experimental colitis and inflammatory bowel diseases. J Clin Invest 117:3097-3106. doi:10.1172/JCI30602

88. Fiocchi C (1998) Inflammatory bowel disease: etiology and pathogenesis. Gastroenterology 115:182-205. doi:10.1016/ S0016-5085(98)70381-6

89. Takeda K, Clausen BE, Kaisho T, Tsujimura T, Terada N, Förster I, Akira S (1999) Enhanced Th1 activity and development of chronic enterocolitis in mice devoid of Stat 3 in macrophages and neutrophils. Immunity 10:39-49. doi:10.1016/S1074-7613(00) 80005-9

90. Girardin SE, Boneca IG, Viala J, Chamaillard M, Labigne A, Thomas G, Philpott DJ, Sansonetti PJ (2003) Nod2 is a general 
sensor of peptidoglycan through muramyl dipeptide (MDP) detection. J Biol Chem 278:8869-8872

91. Inohara N, Nunez G (2003) NODs: intracellular proteins involved in inflammation and apoptosis. Nat Rev Immunol 3:371-382. doi:10.1038/nri1086

92. Bonen DK, Cho JH (2003) The genetics of inflammatory bowel disease. Gastroenterology 124:521-536. doi:10.1053/ gast.2003.50045

93. Chamaillard M, Girardin SE, Viala J, Philpott DJ (2003) Nods, Nalps and Naip: intracellular regulators of bacterial-induced inflammation. Cell Microbiol 5:581-592. doi:10.1046/j.14625822.2003.00304.x

94. Girardin SE, Hugot JP, Sansonetti PJ (2003) Lessons from Nod2 studies: towards a link between Crohn's disease and bacterial sensing. Trends Immunol 24:652-658. doi:10.1016/j. it.2003.10.007

95. Watanabe T, Kitani A, Murray PJ, Strober W (2004) NOD2 is a negative regulator of Toll-like receptor 2-mediated $\mathrm{T}$ helper type 1 responses. Nat Immunol 5:800-808

96. Kobayashi KS, Chamaillard M, Ogura Y, Henegariu O, Inohara N, Nunez G, Flavell RA (2005) Nod2-dependent regulation of innate and adaptive immunity in the intestinal tract. Science 307:731-734. doi:10.1126/science.1104911

97. Maeda S, Hsu LC, Liu H, Bankston LA, Iimura M, Kagnoff MF, Eckmann L, Karin M (2005) Nod2 mutation in Crohn's disease potentiates NF-kappaB activity and IL-1beta processing. Science 307:734-738. doi:10.1126/science.1103685

98. Kamada N, Hisamatsu T, Okamoto S, Chinen H, Kobayashi T, Sato T, Sakuraba A, Kitazume MT, Sugita A, Koganei K, Akagawa KS, Hibi T (2008) Unique CD14 intestinal macrophages contribute to the pathogenesis of Crohn disease via IL23/IFN-gamma axis. J Clin Invest 118:2269-2280

99. van Deventer SJ (2001) Transmembrane TNF-alpha, induction of apoptosis, and the efficacy of TNF-targeting therapies in Crohn's disease. Gastroenterology 121:1242-1246

100. Corazza N, Eichenberger S, Eugster HP, Mueller C (1999) Nonlymphocyte-derived tumor necrosis factor is required for induction of colitis in recombination activating gene (RAG) 2(-/ -) mice upon transfer of CD4(+) CD45RB(hi) T cells. J Exp Med 190:1479-1492. doi:10.1084/jem.190.10.1479

101. Brand S, Sakaguchi T, Gu X, Colgan SP, Reinecker HC (2002) Fractalkine-mediated signals regulate cell-survival and immunemodulatory responses in intestinal epithelial cells. Gastroenterology 122:166-177. doi:10.1053/gast.2002.30329

102. Lucas AD, Chadwick N, Warren BF, Jewell DP, Gordon S, Powrie F, Greaves DR (2001) The transmembrane form of the CX3CL1 chemokine fractalkine is expressed predominantly by epithelial cells in vivo. Am J Pathol 158:855-866

103. Muehlhoefer A, Saubermann LJ, Gu X, Luedtke-Heckenkamp K, Xavier R, Blumberg RS, Podolsky DK, MacDermott RP,
Reinecker HC (2000) Fractalkine is an epithelial and endothelial cell-derived chemoattractant for intraepithelial lymphocytes in the small intestinal mucosa. J Immunol 164:3368-3376

104. Niess JH, Brand S, Gu X, Landsman L, Jung S, McCormick BA, Vyas JM, Boes M, Ploegh HL, Fox JG, Littman DR, Reinecker HC (2005) CX3CR1-mediated dendritic cell access to the intestinal lumen and bacterial clearance. Science 307:254-258. doi:10.1126/science.1102901

105. Mazzucchelli L, Hauser C, Zgraggen K, Wagner HE, Hess MW, Laissue JA, Mueller C (1996) Differential in situ expression of the genes encoding the chemokines MCP-1 and RANTES in human inflammatory bowel disease. J Pathol 178:201-206. doi:10.1002/(SICI)1096-9896(199602)178:2<201::AIDPATH440>3.0.CO;2-4

106. Varol C, Yona S, Jung S (2009) Origins and tissue-contextdependent fates of blood monocytes. Immunol Cell Biol 87:30 38. doi:10.1038/icb. 2008.90

107. Ziegler-Heitbrock HW (2000) Definition of human blood monocytes. J Leukoc Biol 67:603-606

108. Henderson RB, Hobbs JA, Mathies M, Hogg N (2003) Rapid recruitment of inflammatory monocytes is independent of neutrophil migration. Blood 102:328-335. doi:10.1182/blood2002-10-3228

109. Weber C, Belge KU, von Hundelshausen P, Draude G, Steppich B, Mack M, Frankenberger M, Weber KS, Ziegler-Heitbrock HW (2000) Differential chemokine receptor expression and function in human monocyte subpopulations. J Leukoc Biol 67:699-704

110. Taylor PR, Gordon S (2003) Monocyte heterogeneity and innate immunity. Immunity 19:2-4. doi:10.1016/S1074-7613(03)00178-X

111. Tacke F, Alvarez D, Kaplan TJ, Jakubzick C, Spanbroek R, Llodra J, Garin A, Liu J, Mack M, Van Rooijen N, Lira SA, Habenicht AJ, Randolph GJ (2007) Monocyte subsets differentially employ CCR2, CCR5, and CX3CR1 to accumulate within atherosclerotic plaques. J Clin Invest 117:185-194. doi:10.1172/ JCI28549

112. Meng G, Sellers MT, Mosteller-Barnum M, Rogers TS, Shaw GM, Smith PD (2000) Lamina propria lymphocytes, not macrophages, express CCR5 and CXCR4 and are the likely target cell for human immunodeficiency virus type 1 in the intestinal mucosa. J Infect Dis 182:785-791. doi:10.1086/315790

113. Li PF, Dietz R, von Harsdorf R (1999) Superoxide induces apoptosis in cardiomyocytes, but proliferation and expression of transforming growth factor-betal in cardiac fibroblasts. FEBS Lett 448:206-210. doi:10.1016/S0014-5793(99)00370-1

114. Rogler G, Hausmann M, Vogl D, Aschenbrenner E, Andus T, Falk W, Andreesen R, Scholmerich J, Gross V (1998) Isolation and phenotypic characterization of colonic macrophages. Clin Exp Immunol 112:205-215. doi:10.1046/j.1365-2249.1998. 00557.x 